\title{
Ordered arrays of highly oriented single-crystal semiconductor nanoparticles on silicon substrates
}

\author{
Y Lei ${ }^{1,2,3}$, W K Chim ${ }^{3,4}$, J Weissmüller ${ }^{1}$, G Wilde ${ }^{1}$, H P Sun ${ }^{5}$ and \\ X Q Pan $^{5}$ \\ ${ }^{1}$ Forschungszentrum Karlsruhe, Institut für Nanotechnologie, Karlsruhe, 76021, Germany \\ ${ }^{2}$ Institute of Solid State Physics, Chinese Academy of Sciences, Hefei 230031, \\ People's Republic of China \\ ${ }^{3}$ Singapore-MIT Alliance, National University of Singapore, 04-10, 4 Engineering Drive 3, \\ Singapore 117576, Singapore \\ ${ }^{4}$ Department of Electrical and Computer Engineering, National University of Singapore, \\ 4 Engineering Drive 3, Singapore 117576, Singapore \\ ${ }^{5}$ Department of Materials Science and Engineering, The University of Michigan, Ann Arbor, \\ MI 48109, USA
}

E-mail: yong.lei@int.fzk.de and yuanzhilei@yahoo.com

Received 13 April 2005, in final form 1 July 2005

Published 22 July 2005

Online at stacks.iop.org/Nano/16/1892

\begin{abstract}
One of the unsolved problems in the application of nanoparticle arrays is how to precisely control their macroscopic properties based on the microscopic properties of their basic component - the individual nanoparticle. Thus it is highly desirable to fabricate arrays of perfect iso-nanoparticles, which are defined as particles of the same size, structure, and ambient condition. Here we show that ordered semiconductor (indium oxide) single-crystal nanoparticle arrays can be obtained by oxidation of arrayed metal (indium) nanoparticles. The arrayed semiconductor nanoparticles have similar size, shape, crystalline structure and orientation, and ambient condition. Our work is a step closer towards the goal of achieving iso-nanoparticle arrays.
\end{abstract}

(Some figures in this article are in colour only in the electronic version)

\section{Introduction}

Large-scale semiconductor nanoparticle arrays on substrates have attracted growing interest due to their utilization in nanoscale devices, such as microelectronics, optoelectronics, and sensing devices [1-4]. It is highly desirable to control the properties of the nanoparticle array based on the integration of the properties of the individual nanoparticle. However, this is difficult to achieve since the structures and ambient conditions (surrounding nanoparticles) of the arrayed nanoparticles are usually different from each other. A good way to realize these is the fabrication of large-scale nanoparticle arrays composed of iso-nanoparticles, which means that all the arrayed nanoparticles are the same, both in terms of the structure and the ambient condition. A good candidate to this end is highly ordered arrays of highly oriented singlecrystal nanoparticles. The high regularity of the arrays gives rise to the similar size, shape and ambient condition of the nanoparticles while the highly oriented single-crystal nature of the nanoparticles results in the similar crystalline structure of all nanoparticles.

There are several methods for producing nanoparticle arrays on substrates, including in particular electron beam lithography (EBL) [5-7], nanoimprint [8-10], and selfassembly processes $[11,12]$. Usually it is hard to obtain highly oriented single-crystal nanoparticle arrays using these methods. Recently, through the use of alumina membranes as evaporation masks, large-scale ordered nanoparticle arrays were fabricated [13-22]. The process involves the successful transfer of the regularity of the porous alumina into the 

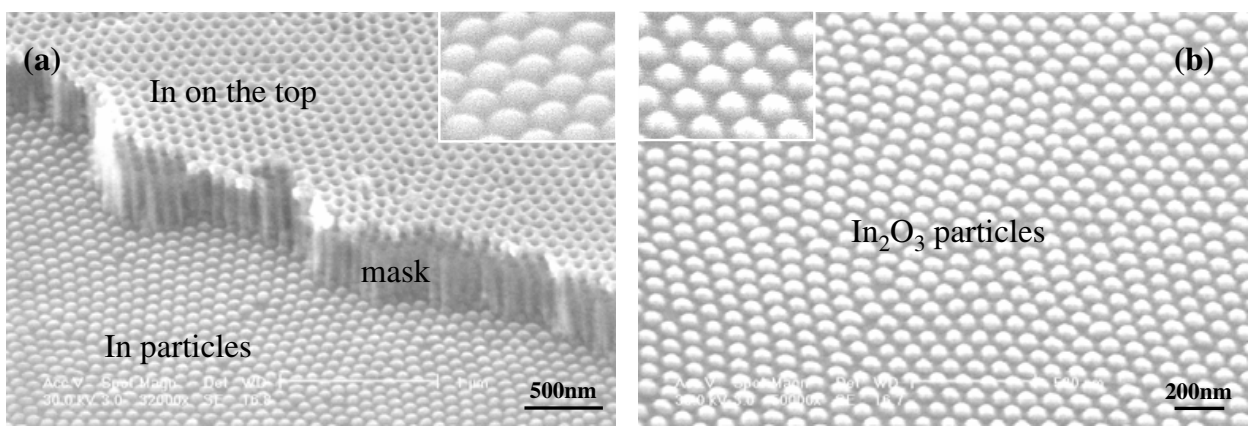

Figure 1. (a) In nanoparticle arrays, with part of the UTAM remaining. Pore diameter, cell size, and thickness of the UTAM are about 75, 105 , and $350 \mathrm{~nm}$, respectively. The average size of the In nanoparticles is about $70 \mathrm{~nm}$. (b) $\mathrm{In}_{2} \mathrm{O}_{3}$ nanoparticle arrays obtained from the oxidation of the In nanoparticles (after the removal of the UTAM); the average particle size is also about $75 \mathrm{~nm}$. The insets in (a) and (b) are the enlarged images.

nanoparticle array. The sizes and the shapes of the nanoparticles can be adjusted by changing the parameters of the alumina masks and the evaporation processes [22]. However, due to the greater difficulty in the evaporation of semiconductors than that of metals, highly oriented semiconductor single-crystal nanoparticle arrays have not yet been fabricated using the method.

Here we report that, using a three-step oxidation process, ordered indium oxide $\left(\mathrm{In}_{2} \mathrm{O}_{3}\right)$ nanoparticle arrays on silicon substrates were fabricated from indium (In) nanoparticle arrays. Each $\operatorname{In}_{2} \mathrm{O}_{3}$ nanoparticle is a single crystal and almost all nanoparticles are oriented in a similar lattice direction, which means a high degree of orientational order of the arrayed nanoparticles. The controlled oxidation during a three-step temperature-time profile, which gives rise to a core-shell structure of the $\mathrm{In} / \mathrm{In}_{2} \mathrm{O}_{3}$, is crucial for the transformation from the In nanoparticles to the $\operatorname{In}_{2} \mathrm{O}_{3}$ single-crystal nanoparticles. The size of the monodisperse nanoparticles can be adjusted from about 10 to $200 \mathrm{~nm}$.

As a well known transparent conducting oxide [23], indium oxide $\left(\mathrm{In}_{2} \mathrm{O}_{3}\right)$ has been widely employed in solar cells [24], flat-panel displays [25], architectural glasses [26] and organic light-emitting diodes [27]. Moreover, $\mathrm{In}_{2} \mathrm{O}_{3}$ films have been demonstrated to work as ultra-sensitive toxic-gas detectors [28]. Very importantly, it has been reported that the gas sensing ability of $\mathrm{In}_{2} \mathrm{O}_{3}$ particles increased significantly by decreasing the particle size [29]. Therefore, the nanometre size of the $\mathrm{In}_{2} \mathrm{O}_{3}$ particles in this paper is expected to result in enhanced sensitivity as gas sensors. Additionally, the high regularity of $\mathrm{In}_{2} \mathrm{O}_{3}$ nanoparticle arrays, especially in the form of single-crystal nanoparticles, may offer much better controllability to the optical properties of the $\mathrm{In}_{2} \mathrm{O}_{3}$ in the above-mentioned applications.

\section{Experimental details}

The entire fabrication process consists of three parts. The first part is the preparation of ultra-thin alumina masks (UTAMs) on the surface of Si substrates. The second part is the thermal evaporation of the In nanoparticle arrays and the removal of the UTAMs. The details of the fabrication of UTAMs, the thermal evaporation of metal, and the removal of the UTAMs can be found in our previous work [22]. Figure 1(a) shows this array on a $\mathrm{Si}$ wafer (with a thin $\mathrm{SiO}_{2}$ surface layer), where part of the UTAM is left behind intentionally to show the whole structure of the UTAM/nanoparticles/substrate. The diameter distribution of the arrayed In nanoparticles is highly monodisperse. The pore diameters of the UTAMs can be adjusted from about 10 to $200 \mathrm{~nm}$ to yield In nanoparticles of corresponding size. The area of the UTAM is several square centimetres with our current set-up and can be as large as several tens of square centimetres.

The third part of the fabrication process is the oxidation of In nanoparticles to $\operatorname{In}_{2} \mathrm{O}_{3}$ nanoparticles. For low meltingpoint metals like In, a conventional oxidation process with a relatively fast temperature increment will cause the granulation of the metal film or the agglomeration of the metal nanoparticles [30-32]. Usually it is impossible for the metal to keep the original shape after the oxidation. In the case of dense particles on substrates, neighbouring molten In particles will migrate along the surface and agglomerate into large blocks of In. All these will destroy the high regularity of the nanoparticles during the oxidation process in our case. Here we used a three-step oxidation process to realize the transformation of In nanoparticles to $\operatorname{In}_{2} \mathrm{O}_{3}$ nanoparticles: in the first step, the temperature was increased to $146^{\circ} \mathrm{C}$, which is around the melting point of the In nanoparticles (for In nanoparticles with diameters of several tens of nanometres, the melting point is about $10^{\circ} \mathrm{C}$ lower than the melting point of bulk In $\left(156.61{ }^{\circ} \mathrm{C}\right)$ ) [33], and held at $146^{\circ} \mathrm{C}$ for $1 \mathrm{~h}$ (the preheating process). In the second step, the temperature ramp process, the temperature was ramped to $800^{\circ} \mathrm{C}$ at a rate of $10^{\circ} \mathrm{C} \mathrm{min}^{-1}$; this process took about $1 \mathrm{~h}$. The third step (the final oxidation process) is holding the temperature at $800^{\circ} \mathrm{C}$ for $2 \mathrm{~h}$ to complete the oxidation. The whole process, including the initial heating to $146^{\circ} \mathrm{C}$, was performed in a tube furnace with a constant flow of oxygen at atmospheric pressure.

The SEM images were obtained using a field-emission scanning electron microscope (Philips XL-30 FEG). X-ray diffraction patterns were captured by a general area detector diffraction system, which was equipped with a high sensitive area detector (HI-STAR) that is especially suitable for those samples with texture and small quantity. High resolution transmission electron microscopy (HRTEM) measurements were carried out on the CM300FEG instrument (with a $300 \mathrm{kV}$ high voltage and field emission gun) and a JEOL3010 instrument (with a $300 \mathrm{kV}$ high voltage). 

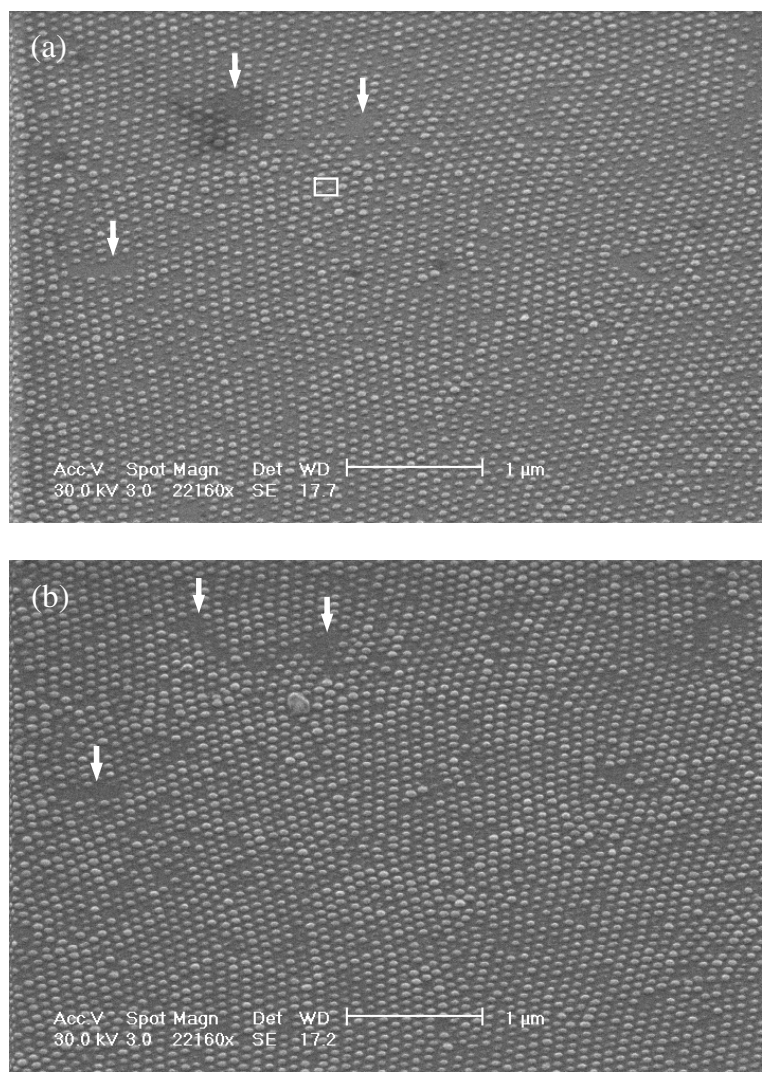

Figure 2. The 'simulated in situ SEM measurement' of the change from the In nanoparticles (a) to $\mathrm{In}_{2} \mathrm{O}_{3}$ nanoparticles (b). The substrate is $\mathrm{Si}$ wafer with a thin $\mathrm{SiO}_{2}$ surface layer.

\section{Results and discussion}

Figure 1(b) shows the oxidized nanoparticle arrays. It clearly shows that there is no obvious change of the nanoparticle arrays after oxidation: the monodisperse nanoparticles are arrayed on the substrate with high regularity. Because figures 1(a) and (b) are not obtained exactly from the same area, we performed a 'simulated in situ SEM measurement' (figure 2), where the same area was investigated before (figure 2(a)) and after the oxidation (figure 2(b)). Figures 2(a) and (b) are captured in exactly the same area of the same sample. Normally, due to the overlap of the two anodization processes, pore arrays on the edge of the alumina mask are not very regular, resulting in In nanoparticle arrays with many defects (figure 2(a)). In the SEM measurement, we intentionally selected this defect area in the In nanoparticle sample so that we can locate the same area in the $\mathrm{In}_{2} \mathrm{O}_{3}$ nanoparticle sample (figure 2(b)) by using the defects as the locating spots. The whole in situ process is the following. First, we selected the area and captured the image (figure 2(a)). Then we zoomed out to $25 \%$ and captured another image. We repeated the same zoom-out and image-capture operation (usually six times) till we went into the millimetre region. After the In nanoparticle sample had been heat-treated and changed to an $\mathrm{In}_{2} \mathrm{O}_{3}$ nanoparticle sample, we used the images captured on the In sample to locate the same area (figure 2(b)) in the $\mathrm{In}_{2} \mathrm{O}_{3}$ sample by zooming in $400 \%$ also six times. Three representative defects, used in registering and identifying similar areas in the two images,

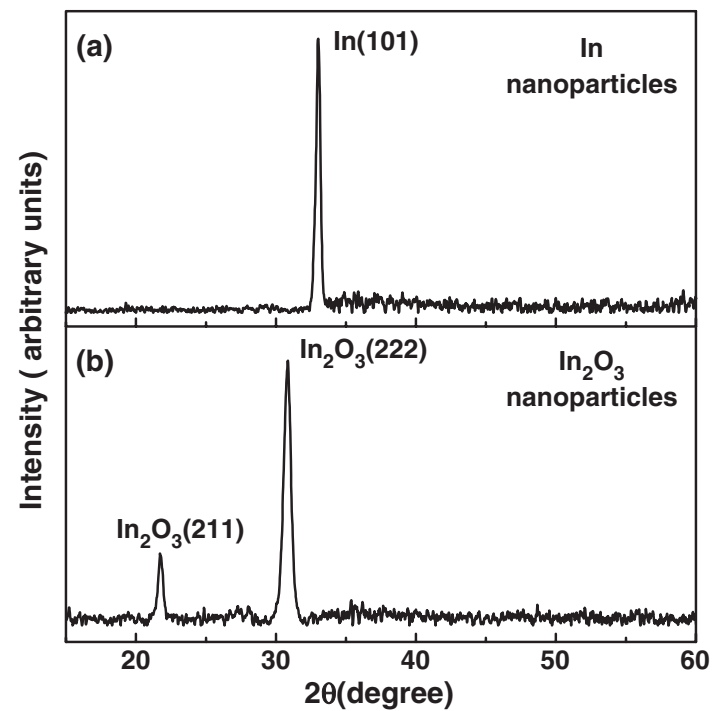

Figure 3. X-ray diffraction spectra of the In and $\operatorname{In}_{2} \mathrm{O}_{3}$ nanoparticle arrays on $\mathrm{SiO}_{2} / \mathrm{Si}$ substrates showing the oriented nature of the In and $\mathrm{In}_{2} \mathrm{O}_{3}$ nanoparticles. (a) In nanoparticles. (b) $\mathrm{In}_{2} \mathrm{O}_{3}$ nanoparticles. The diameters of the $\mathrm{In}$ and $\mathrm{In}_{2} \mathrm{O}_{3}$ nanoparticles for the XRD measurement are about 45-48 nm (pore diameter, cell size and thickness of the UTAM which is used here are about 55, 105, and $200 \mathrm{~nm}$, respectively).

are shown arrowed in white. Clearly, it can be seen that there is no obvious change of the nanoparticles and their array regularity after oxidation ${ }^{6}$. In particular, there is almost no agglomeration in the oxidation process (only four In particles in the small square in figure 2(a) melted into a large $\operatorname{In}_{2} \mathrm{O}_{3}$ particle in figure 2(b)). We have applied the same three-step oxidation process to tin $(\mathrm{Sn})$ and zinc $(\mathrm{Zn})$ nanoparticle arrays and successfully obtained ordered $\mathrm{SnO}_{2}$ and $\mathrm{ZnO}$ nanoparticle arrays. This implies that the process can be applied more generally to other metals in fabricating ordered metal oxide nanoparticle arrays.

XRD measurement (figure 3) confirms that the In nanoparticles (indexed as tetragonal In, space group (SG) $I 4 / \mathrm{mmm}$ (139)) have been completely converted to $\mathrm{In}_{2} \mathrm{O}_{3}$ nanoparticles (indexed as cubic $\mathrm{In}_{2} \mathrm{O}_{3}$, SG Ia3 (206)) after the oxidation process. Moreover, the as-evaporated In nanoparticles exhibit a (101) preferred orientation while the $\operatorname{In}_{2} \mathrm{O}_{3}$ nanoparticles show a (111) preferred orientation. It has been reported that thermal-evaporated In films and subsequently oxidized $\mathrm{In}_{2} \mathrm{O}_{3}$ films, on amorphous-surfaced substrates such as $\mathrm{SiO}_{2} / \mathrm{Si}$ and glass, showed a (101) preferred orientation for In and a (111) preferred orientation for $\mathrm{In}_{2} \mathrm{O}_{3}$ [30-32]. This preferred orientation was revealed by the intensity ratio differences among the XRD peaks and is considered as a natural result of the thermal evaporation process of indium [30-32]. In our case, only one or two peaks appear (for In (101) and for $\operatorname{In}_{2} \mathrm{O}_{3}$ (222) and (211)) in the XRD spectra, which is different from the multi-peaked XRD spectra of the thermal-evaporated films in [28-30]. This indicates a higher degree of orientational order of the

6 Because the calculated volume ratio of $\mathrm{In}_{2} \mathrm{O}_{3}$ (tetragonal, $\mathrm{I} 4 / \mathrm{mmm}$ (139)) to In (cubic, $\operatorname{Ia} 3$ (206)) is 1.230 , the extension ratio in one dimension is only about $0.071\left((0.071+1)^{3}=1.230\right)$. Therefore, in the SEM and TEM images, there is no obvious change of the size of the nanoparticles after the oxidation. 


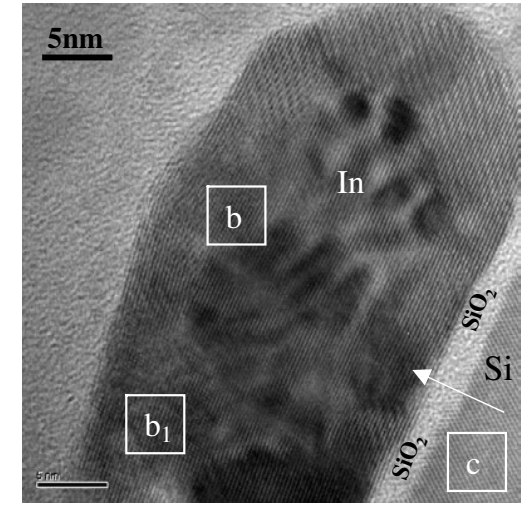

a

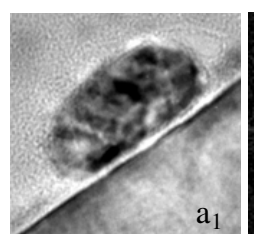

$\mathrm{a}_{1}$
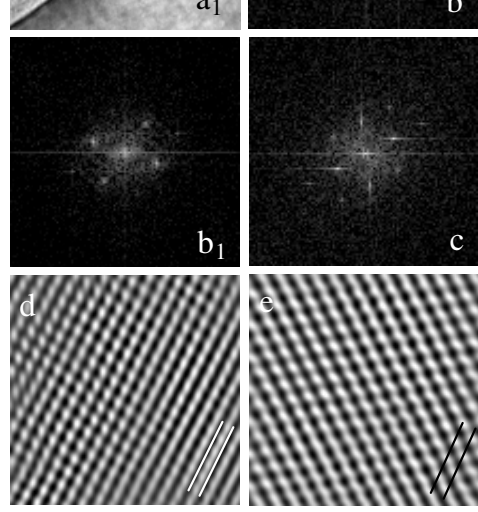

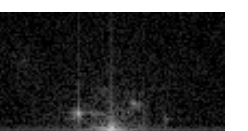

b

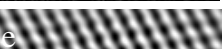

.
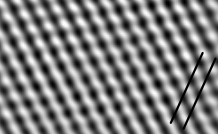
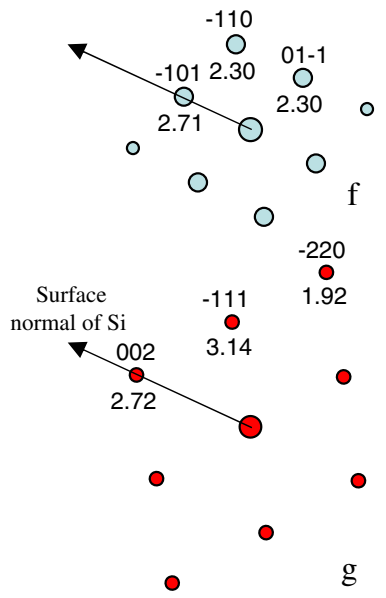

Figure 4. Microstructures of an In nanoparticle (the same sample as that in figure 3(a)) studied by cross-sectional HRTEM measurement. (a) This In nanoparticle on the surface of $\mathrm{SiO}_{2} / \mathrm{Si}$. ( $\left.\mathrm{a}_{1}\right) \mathrm{A}$ low-magnification image of the In nanoparticle. (b), (b $)_{1}$, (c) The Fourier transformation patterns of the same large squared areas $b, b_{1}$ and $c$ in (a), which are in the In nanoparticle and the Si substrate respectively. (d), (e) The Fourier filtered lattice images of the areas b and c in (a). (f), (g) The simulated electron diffraction patterns along the [111] direction of In (sys tetragonal, SG I4/mmm (139)) and the [110] direction of Si; both of them have been rotated so that they fit the patterns in (b) and (c) exactly. The three arrows in (a), (f) and (g) are the surface normal of the $\mathrm{Si}(001)$ wafer which is defined in (g). The relative orientation relationship between In and Si was identified as $\operatorname{In}(101)[111] \| \operatorname{Si}(002)[110]$. The white and black parallels in (d) and (e) indicate the lattice distances of the $\operatorname{In}(101)$ and $\mathrm{Si}(002)$ plane. There are about 22 lattice distances along the surface normal direction in (d) and (e). Thus the lattice distance ratio of $\operatorname{In}(101)$ to $\operatorname{Si}(002)$ is about $1: 1$

nanoparticles in our case, which may be related to the ordered channels of the UTAMs, that add a spatial confinement to the evaporation process and lead to a single growth orientation of the nanoparticles.

Detailed cross-sectional HRTEM measurement and analyses confirm the highly oriented structures of the In and $\mathrm{In}_{2} \mathrm{O}_{3}$ nanoparticles. Figure 4 shows the microstructure analysis of an In nanoparticle. The substrate for this sample is n-type (001) $\mathrm{Si}$ covered with a $2 \mathrm{~nm}$ thick $\mathrm{SiO}_{2}$ layer. Figure 4(a) is a cross-sectional HRTEM image of an In nanoparticle. It can be seen that the lattice directions are almost the same in each part of the particle, indicating the singlecrystal nature of the In nanoparticle. However, there are some lattice intensity distributions, especially in the inner parts of the In nanoparticles, suggesting the presence of regions with slight misorientations giving rise to a Moiré-like pattern. We performed Fourier transformation (figures 4(b) and (c)) and Fourier image filtering (figures 4(d) and (e)) of the squared areas (b) and (c) in figure 4(a), which are in the In particle and the Si substrate respectively. To study the relative orientation relationship between $\mathrm{In}$ and $\mathrm{Si}$, we performed the simulation of electron diffraction patterns along the [111] direction of In (sys tetragonal, SG I4/ $\mathrm{mmm}$ (139)) (figure 4(f)) and the [110] direction of Si (figure $4(\mathrm{~g})$ ). Both of the simulated patterns have been rotated to fit the patterns in figures 4(b) and (c). The surface normal of the $\mathrm{Si}(100)$ substrate is defined by the arrow in figure $4(\mathrm{~g})$. We moved the arrow to figure 4(f) and found that the $\operatorname{In}[101]$ direction has almost the same direction as the surface normal of $\mathrm{Si}$, which indicates that the $\operatorname{In}(101)$ plane (the white parallel lines in figure 4(d)) is almost parallel to the $\mathrm{Si}(002)$ plane (the black parallel lines in figure 4(e)). The lattice distance ratio of $\operatorname{In}(101)$ to $\mathrm{Si}(002)$ is about unity (in figures 4(d) and (e)), which is in good agreement with the standard value of 2.71:2.72. The Fourier transformation pattern of another squared area $b_{1}$ in figure 4(a) is shown in figure $4\left(b_{1}\right)$. It shows that there is only a very small relative rotation angle between region $b$ and $b_{1}$. This further confirms that the In nanoparticle is a defect-containing but highly crystallized particle, in other words an imperfect single crystal.

We also performed similar HRTEM analysis on the $\operatorname{In}_{2} \mathrm{O}_{3}$ nanoparticles (figure 5). It is found that the $\mathrm{In}_{2} \mathrm{O}_{3}$ nanoparticles are single-crystal nanoparticles (figure 5(a)). It can be seen that the lattice directions are the same in each part of the particle, and there are no visible defects or variation in the lattice orientation. The highly crystalline nature can also be seen in the Fourier transformation pattern shown in figure 5(b). In contrast to the smooth surface of the In nanoparticle (figure 4(a $\left.\mathrm{a}_{1}\right)$ ), the $\mathrm{In}_{2} \mathrm{O}_{3}$ nanoparticle is facetted. The thicker $\mathrm{SiO}_{2}$ layer of about $5 \mathrm{~nm}$ thickness in figure 5(a), as compared to the $2 \mathrm{~nm}$ thickness of the $\mathrm{SiO}_{2}$ layer in figure 4(a), is the natural result of the oxidation process. The simulated electron diffraction patterns along the [110] direction of $\mathrm{In}_{2} \mathrm{O}_{3}$ (sys cubic, SG Ia3 (206)) (figure 5(f)) and Si (figure 5(g)) were rotated to fit the Fourier transformation patterns in figures 5(b) and (c), respectively. The $\mathrm{In}_{2} \mathrm{O}_{3}$ [111] direction is almost the same as the surface-normal direction of $\mathrm{Si}$ (arrows in figures 5(f) and (g)), indicating that the $\mathrm{In}_{2} \mathrm{O}_{3}(222)$ plane (the white parallel lines in figure $5(\mathrm{~d})$ ) is almost parallel to the $\mathrm{Si}(002)$ plane (the white parallel lines in figure $5(\mathrm{e})$ ). The lattice distance ratio of $\mathrm{In}_{2} \mathrm{O}_{3}(222)$ to $\mathrm{Si}(002)$ is about 1.077 (in figures 5(d) and (e)), which is in good agreement with the standard value of 1.074 (2.92:2.72). 


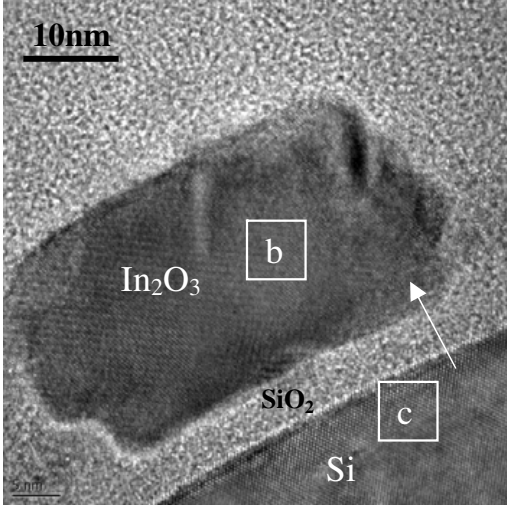

a

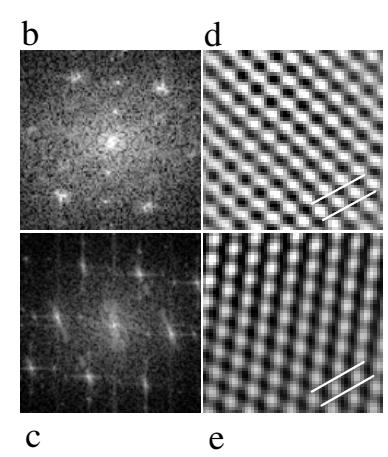

$\mathrm{c}$

$\mathrm{e}$

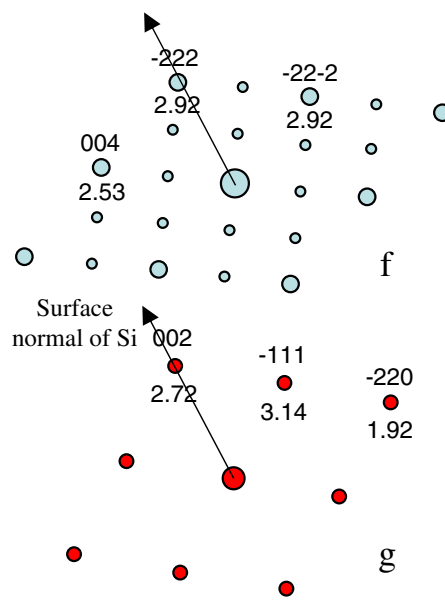

Figure 5. Microstructures of an $\mathrm{In}_{2} \mathrm{O}_{3}$ nanoparticle (the same sample as that in figure 3(b)) studied by cross-sectional HRTEM measurement. (a) This $\mathrm{In}_{2} \mathrm{O}_{3}$ nanoparticle on the surface of $\mathrm{SiO}_{2} / \mathrm{Si}$. (b) and (c) The Fourier transformation patterns of the same-large squared areas b and $c$ in (a), which are in the $\mathrm{In}_{2} \mathrm{O}_{3}$ nanoparticle and the Si substrate respectively. (d) and (e) are the Fourier filtered lattice images of the areas $\mathrm{b}$ and $\mathrm{c}$ in (a). (f), (g) The simulated electron diffraction patterns along the [110] direction of $\mathrm{In}_{2} \mathrm{O}_{3}$ ( $(\mathrm{sys}$ cubic, $\mathrm{SG} I \mathrm{a} 3$ (206)) and $\mathrm{Si}$, both of them have been rotated so that they fit the patterns in (b) and (c) exactly. The three arrows in (a), (f) and (g) are the surface normal of the $\mathrm{Si}(001)$ wafer which is defined in $(\mathrm{g})$. The relative orientation relationship between $\mathrm{In}_{2} \mathrm{O}_{3}$ and $\mathrm{Si}_{\text {was }}$ identified as $\mathrm{In}_{2} \mathrm{O}_{3}(222)[110] \| \mathrm{Si}(002)[110]$. The white parallels in (d) and (e) indicate the lattice distances of the $\mathrm{In}_{2} \mathrm{O}_{3}(222)$ and $\mathrm{Si}(002)$ plane. There is about 13 lattice distances for $\operatorname{In}_{2} \mathrm{O}_{3}(222)$ plane and about 14 lattice distances for $\mathrm{Si}(002)$ plane along the surface normal direction in (d) and (e). Thus the lattice distance ratio of $\mathrm{In}_{2} \mathrm{O}_{3}(222)$ to $\mathrm{Si}(002)$ is about 1.077.

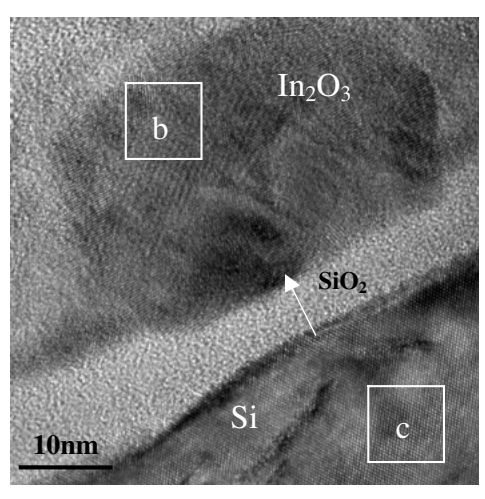

a
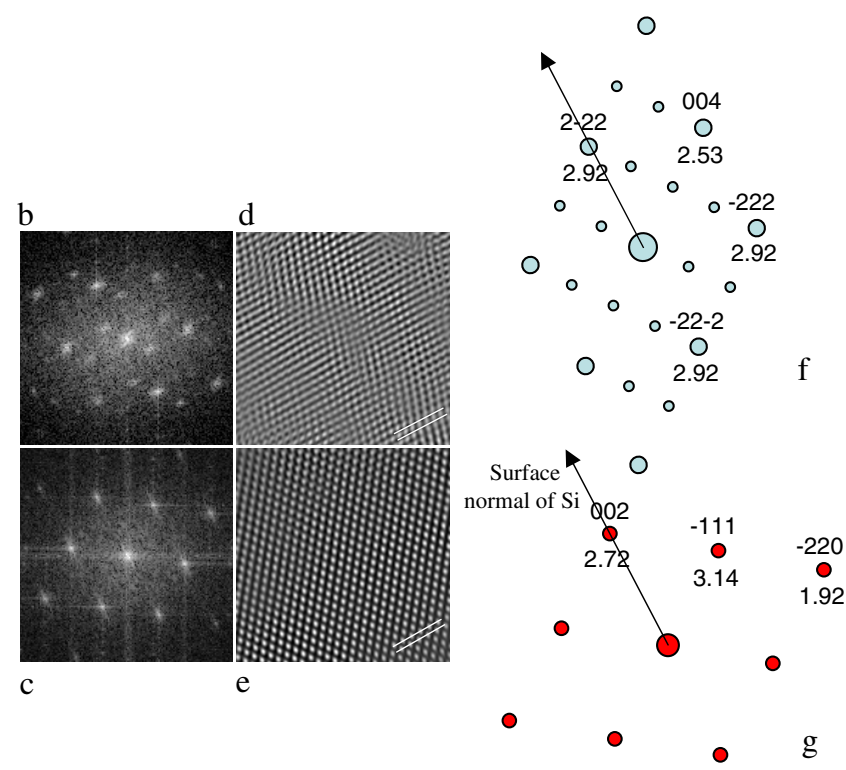

Figure 6. Microstructures of another $\mathrm{In}_{2} \mathrm{O}_{3}$ nanoparticle (same sample as that in figure 3(b)) studied by cross-sectional HRTEM measurement. (a) This $\mathrm{In}_{2} \mathrm{O}_{3}$ nanoparticle on the surface of $\mathrm{SiO}_{2} / \mathrm{Si}$. (b), (c) The Fourier transformation patterns of the squared areas b and c in (a), which are in the $\mathrm{In}_{2} \mathrm{O}_{3}$ nanoparticle and the Si substrate respectively. (d), (e) The Fourier filtered lattice images of areas b and c in (a). (f), (g) The simulated electron diffraction patterns along the [110] direction of $\mathrm{In}_{2} \mathrm{O}_{3}$ (sys cubic, SG Ia3 (206)) and Si; both of them have been rotated so that they fit the patterns in (b) and (c) exactly. The three arrows in (a), (f) and (g) are the surface normal of the $\mathrm{Si}(001)$ wafer. The relative orientation relationship between $\mathrm{In}_{2} \mathrm{O}_{3}$ and $\mathrm{Si}$ was identified as $\mathrm{In}_{2} \mathrm{O}_{3}(222)[110] \| \mathrm{Si}(002)$ [110].

We performed the same HRTEM microstructure analysis on other $\mathrm{In}_{2} \mathrm{O}_{3}$ nanoparticles (see figure 6 for the microstructures of another $\operatorname{In}_{2} \mathrm{O}_{3}$ nanoparticle which is similar to the results in figure 5) and found that the relative orientation relationships between $\mathrm{In}_{2} \mathrm{O}_{3}$ nanoparticles and $\mathrm{Si}$ substrates are all approximately $\mathrm{In}_{2} \mathrm{O}_{3}(222)$ [110] $\| \mathrm{Si}(002)[110]$. There are only very small rotation angles between the different $\operatorname{In}_{2} \mathrm{O}_{3}$ particles. This indicates that, the arrayed $\operatorname{In}_{2} \mathrm{O}_{3}$ nanoparticles have the similar crystalline orientation.
Based on the above, after the oxidation process, the particles are converted from In metal, containing defects but otherwise single crystalline, to $\operatorname{In}_{2} \mathrm{O}_{3}$ single-crystal particles with no defects. To understand this transformation in the oxidation process, we studied the intermediate state between In and $\mathrm{In}_{2} \mathrm{O}_{3}$. Figure 7(a) is the cross-sectional HRTEM image of an intermediate nanoparticle in the sample after the preheating process, but before the temperature ramp process. We found that, at this stage, the particles have a metal core covered by 

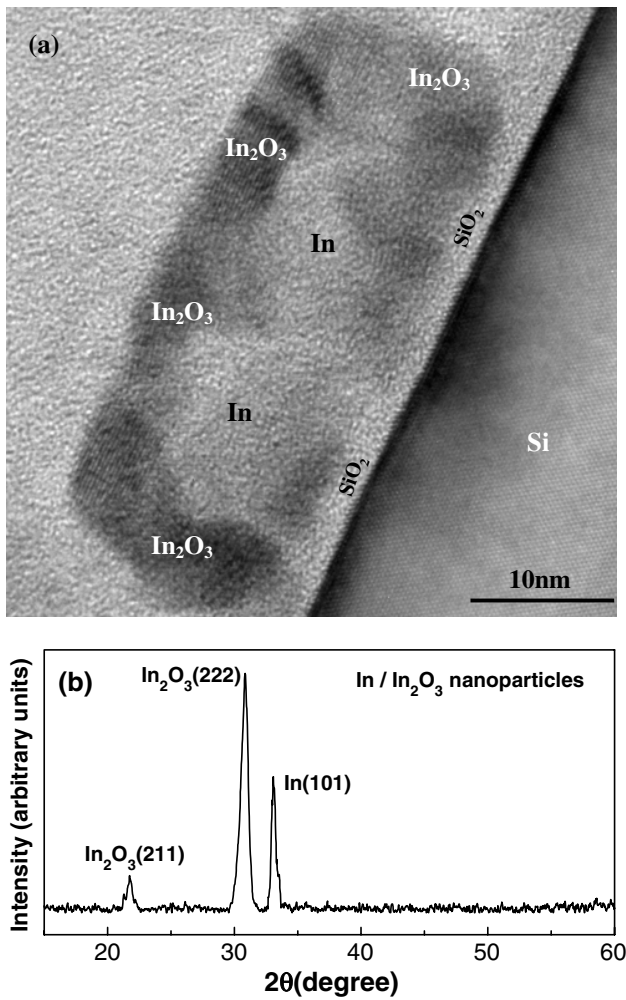

Figure 7. Shell structures of the intermediate nanoparticles after the preheating process and before the temperature ramp process. (a) An intermediate nanoparticle on the surface of $\mathrm{SiO}_{2} / \mathrm{Si}$. (b) The XRD spectrum of the sample in (a). The thickness of the $\mathrm{In}_{2} \mathrm{O}_{3}$ shell is about 5-6 nm.

an oxide shell. XRD measurement in figure 7(b) confirmed that the particle is composed of $\operatorname{In}_{2} \mathrm{O}_{3}$ and In. The outer shell is $\mathrm{In}_{2} \mathrm{O}_{3}$, as confirmed by the lattice distance measurement, with a thickness of 5-6 $\mathrm{nm}$. We also found that, after the temperature ramp process from 146 to $800{ }^{\circ} \mathrm{C}$, the thickness of the oxide shell grows from about 5-6 nm to about $16 \mathrm{~nm}$. This indicates that, at the beginning of the preheating process, an oxide shell is formed at the surface of the In particle. As the oxidation progresses, the inner In reacts with the oxygen at the core-shell interface, thickens the shell gradually, and finally results in the $\mathrm{In}_{2} \mathrm{O}_{3}$ particle.

A reasonable growth mechanism of the $\operatorname{In}_{2} \mathrm{O}_{3}$ singlecrystal nanoparticles is described as follows. At the beginning of the oxidation, there is a thin oxide shell formed on the surface of the In nanoparticle. In the preheating process, the partially melted inner In core $\left(146^{\circ} \mathrm{C}\right.$ is around the melting point of the nanometre-sized In particle) [33] is oxidized at the coreshell interface by the diffused oxygen from the outer surface of the shell, thus thickening the shell gradually. Because the temperature is just around the melting point of In, the growth rate of the oxide shell is quite small, about 5-6 $\mathrm{nm} \mathrm{h}^{-1}$. This slowly formed shell is extremely crucial to the formation of $\mathrm{In}_{2} \mathrm{O}_{3}$ nanoparticles. For the conventional single-step oxidation process, it is usually impossible to form a stable shell at the surface since the melted In will 'bump into' and break any newly formed oxide shell. In our case, after the preheating step, a relatively thick and stable oxide shell has been formed before the sample undergoes subsequent higher temperature processes. This is the reason why this three-step oxidation process can realize the transformation of In nanoparticles to $\mathrm{In}_{2} \mathrm{O}_{3}$ nanoparticles. In the following temperature ramp and final oxidation process, the melted inner In core will be further oxidized, with a much higher transformation rate, at the coreshell interface until a single-crystal $\mathrm{In}_{2} \mathrm{O}_{3}$ particle is formed.

As indicated above, for both $\mathrm{In}$ and $\mathrm{In}_{2} \mathrm{O}_{3}$ nanoparticles, the $\mathrm{In}(101)$ planes and the $\mathrm{In}_{2} \mathrm{O}_{3}(222)$ planes are approximately parallel to the $\mathrm{Si}(002)$ plane. However, because there is an amorphous $\mathrm{SiO}_{2}$ layer on the top of the (001) $\mathrm{Si}$ wafer, the crystalline growth direction of the In nanoparticles should have no relation with the $\mathrm{Si}(001)$ plane but with the surface plane of the $\mathrm{SiO}_{2} / \mathrm{Si}$ substrate. The (101) plane of the thermally evaporated In is actually parallel to the surface plane of the substrates $\left(\mathrm{SiO}_{2}\right)$, which is approximately parallel to the $\mathrm{Si}(001)$ plane. This (101) preferred orientation of the In nanoparticles, as mentioned above, is the natural result of the thermal evaporation of indium on amorphous-surfaced substrates [30-32]. In fact, similar observations, i.e. a preferred growth orientation of separately nucleating materials on amorphous substrates, has been reported [34]. This behaviour could be related to so-called 'two-dimensional nucleation and layered growth', where nucleation rate and growth rate for different orientations of the lattice of the deposited materials show large differences. Additionally, the surface free energy of different planes with any substrate, including amorphous ones, might be strongly different. Such a situation would favour the selection of the nucleating plane with lowest interface free energy. Thus, growth would commence in the direction perpendicular to that plane for a large fraction of the particles, resulting in a high degree of orientational ordering. Moreover, the (111) preferred orientation of the $\mathrm{In}_{2} \mathrm{O}_{3}$ nanoparticles should originate from the (101) preferred orientation of the In nanoparticles.

It should be mentioned that the pore arrangement of UTAMs is usually far from an ideally packed hexagonal columnar array over a sizable region of, say, millimetre dimensions. The defect-free areas of the pore arrays are typically several square micrometres. Thus, the regularity of the metal nanoparticle array, and the resultant metal oxide array, is not entirely perfect as this is dependent on the regularity of the alumina membrane pore array used as the evaporation mask. However, by increasing the anodization time [35] or using a pretextured process [36-38], longrange-ordered pore arrays can be obtained with quite a large defect-free area, even of the order of several square millimetres [36-38]. Thus, an ideally regular metal oxide nanoparticle array, with a reasonably large defect-free area, could potentially be obtained by using an alumina membrane as the evaporation mask.

\section{Conclusion}

In summary, we report the first fabrication of ordered arrays of $\mathrm{In}_{2} \mathrm{O}_{3}$ single-crystal nanoparticles based on a precisely controlled oxidation of arrayed In nanoparticles. The arrayed $\mathrm{In}_{2} \mathrm{O}_{3}$ nanoparticles have the similar crystalline orientation, with the $\mathrm{In}_{2} \mathrm{O}_{3}(222)$ planes approximately parallel to the surface plane of the substrates. The size of the monodisperse $\mathrm{In}_{2} \mathrm{O}_{3}$ nanoparticles can be adjusted from about 10 to $200 \mathrm{~nm}$. 


\section{Acknowledgments}

We thank Shijie Wang for the assistance in the HRTEM measurement, Poh-Chong Lim for the XRD measurement and Shuwen Zhang for the preparation of the drawing. Y Lei is grateful for the research fellowships from the Alexander von Humboldt Foundation and the Singapore-MIT Alliance.

\section{References}

[1] Manna L, Milliron D J, Meisel A, Scher E C and Alivisatos A P 2003 Nat. Mater. 2382

[2] Li L S and Alivisatos A P 2003 Adv. Mater. 15408

[3] McMillan R A, Paavola C D, Howard J, Chan S L, Zaluzec N J and Trent J D 2002 Nat. Mater 1247

[4] Trindade T, O'Brien P and Pickett N L 2001 Chem. Mater. 13 3843

[5] Valenta J, Juhasz R and Linnros J 2002 J. Lumin. 9815

[6] Clendenning S B et al 2004 Adv. Mater. 16215

[7] Haynes C L, McFarland A D, Zhao L L, Van Duyne R P, Schatz G C, Gunnarsson L, Prikulis J, Kasemo B and Kall M 2003 J. Phys. Chem. B 1077337

[8] Kuo C W, Shiu J Y, Cho Y H and Chen P 2003 Adv. Mater. 15 1065

[9] Haynes C L, McFarland A D, Smith M T, Hulteen J C and Van Duyne R P 2002 J. Phys. Chem. B 1061898

[10] Chou S Y, Krauss P R and Renstrom P J 1996 Science 27285

[11] Puntes Y F, Krishnan K M and Alivisatos A P 2001 Science 2912115

[12] Sun S, Murray C B, Weller D, Folks L and Moser A 2000 Science 2871989

[13] Masuda H and Satoh M 1996 Japan. J. Appl. Phys. 35 L126

[14] Masuda H, Yasui K and Nishio K 2000 Adv. Mater. 121031

[15] Cheng G and Moskovits M 2002 Adv. Mater. 141567

[16] Sander M S and Tan L S 2003 Adv. Funct. Mater. 13393

[17] Wu Z H, Mei X, Kim D, Blumin M, Ruda H E, Liu J Q and Kavanagh K L 2003 Appl. Phys. Lett. 833368
[18] Lei Y, Yeong K S, Thong J T L and Chim W K 2004 Chem. Mater. 162757

[19] Chen Z, Lei Y, Chew H G, Teo L W, Choi W K and Chim W K 2004 J. Cryst. Growth 268560

[20] Lei Y, Chim W K, Sun H P and Wilde G 2005 Appl. Phys. Lett. 86103106

[21] Lei Y and Chim W K 2005 J. Am. Chem. Soc. 1271487

[22] Lei Y and Chim W K 2005 Chem. Mater. 17580

[23] Ginley D S and Bright C 2000 Mater. Res. Soc. Bull. 2515

[24] Hara K, Sayama K and Arakawa H 2000 Sol. Energy Mater. Sol. Cells 62441

[25] Aoshima Y, Miyazaki M, Sato K, Akao Y, Takaki S and Adachi K 2000 Japan. J. Appl. Phys. 1394884

[26] Grivas C, Mailis S, Eason R W, Tzamali E and Vainos N A 2002 Appl. Phys. A 74457

[27] Kim H, Horwitz J S, Kushto G P, Qadri S B, Kafafi Z H and Chrisey D B 2001 Appl. Phys. Lett. 781050

[28] Liess M 2002 Thin Solid Films 410183

[29] Gurlo A, Ivanovskaya M, Barsan N, Schweizer-Berberich M, Weimar U, Gopel W and Dieguez A 1997 Sensors Actuators B $\mathbf{4 4} 327$

[30] Kolluri S V and Chandorkar A N 1993 Thin Solid Films 23039

[31] Lee M S, Choi W C, Kim E K, Kim C K and Min S K 1996 Thin Solid Films 2791

[32] Parent P, Dexpert H, Tourillon G and Grimal J M 1992 J. Electrochem. Soc. 139276

[33] Zayed M K, Hegazy M S and Elsayed-Ali H E 2004 Thin Solid Films 449254

[34] Wang M, Zhong S, Yin X B, Zhu J M, Peng R W, Wang Y, Zhang K Q and Ming N B 2001 Phys. Rev. Lett. 863827

[35] Masuda H and Fukuda K 1995 Science 2681466

[36] Masuda H, Yamada H, Satoh M and Asoh H 1997 Appl. Phys. Lett. 712770

[37] Asoh H, Nishio K, Nakao M, Tamamura T and Masuda H 2001 J. Electrochem. Soc. 148 B152

[38] Masuda H, Yasui K, Sakamoto Y, Nakaoi M, Tamamura T and Nishio K 2001 Japan. J. Appl. Phys. 40 L1267 